Original Research / Özgün Araştırma

\title{
Examination of Healthy Lifestyle Behaviours in Older Adults with Chronic Disease
}

\section{Kronik Hastalı̆̆ $\quad$ Olan Yaşlılarda Sağlıklı Yaşam Biçimi Davranışlarının İncelenmesi}

\author{
Medine Yılmaz ${ }^{* 1}$, Gülçin Uyanık ${ }^{1}$,Emine Böckün², Yasemin Tokem ${ }^{1}$, Nil Tekin ${ }^{3}$
}

\begin{abstract}
Introduction: The purpose of this study is to determine behaviours of healthy life style of the old people with chronic disease. Methods: The study was carried out with old people aged 60 above who can perform daily life activities independently and having at least one of the diagnoses of cancer, hypertension and diabetes, staying at a residential and nursing home (n:304). Data were collected by use of old people interview form and scale of Healthy Life Style Behaviours-II (HLSB-II). Results: Age average of the individuals involved in the study is $78.9 \pm 7.6$ and $67.1 \%$ were women. $5.3 \%$ of old people (n:16) had cancer, $26 \%$ (n:79) were DM, 49.7\% (n:151) were HT patient and $19.1 \%$ (n:58) had more than one chronic disease. It was determined that BMI values were higher in old people with more than one chronic disease and lower in old people with cancer $(\mathrm{p}<0.001)$. As the term of disease of old people with more than one chronic disease extends, total score of HLSB-II lowers ( $\mathrm{p}<0.01$ ). Scores of health responsibility of cancer patients, scores of sub-scale of physical activity, stress management and moral development of diabetes old people are higher $(\mathrm{p}<0.05)$. Conclusion: Results show that behaviors of healthy life style of old people with diabetes are better than old people having the diagnosis of cancer and hypertension. Development of programs to increase healthy lifestyle for old people with the diagnoses of cancer and hypertension will contribute to active aging process and increase of life quality.
\end{abstract}

Key words: Hypertension, diabetes, cancer, healthy lifestyle behavior

\section{ÖZET}

Giriş: $\mathrm{Bu}$ araştırmanın amacı kanser, hipertansiyon, diyabet tanısı olan yaşlı bireylerin sağlıklı yaşam biçimi davranışlarının belirlenmesidir. Yöntem: Araștırma bir Yaşıı Bakım ve Rehabilitasyon Merkezinde kalan, kanser, hipertansiyon ve diyabet tanılarından en az birine sahip olan, günlük yaşam aktivitelerini bağımsız olarak yerine getirebilen 60 yaş üzerindeki yaşlılarla yürütülmüştür (n:304). Veriler Yaşlı Görüșme Formu ve Sağlıklı Yaşam Biçimi Davranışları Ölçeği-II (HLSB-II) kullanılarak toplanmıștır. Bulgular:

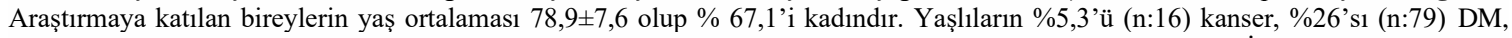
\%49,7'si (n:151) HT hastası olup \%19,1'inin (n:58) birden fazla kronik hastalığı vardır. Kanserli bireylerin BKİ değerinin daha düşük, birden fazla kronik hastalığı olan yaşlıların BKİ değerlerinin daha yüksek olduğu belirlenmiştir $(\mathrm{p}<0,001)$. Birden fazla kronik hastalığı olan yaşlıların hastalık süresi arttıkça yaşam biçimi toplam puanı düşmektedir $(\mathrm{p}<0,01)$. Kanserli yaşlıların sağlık sorumluluğu daha yüksek iken, diyabetli yaşlıların fiziksel aktivite, stres yönetimi ve manevi gelişim durumları daha yüksektir $(\mathrm{p}<0,05)$. Sonuç: Sonuçlar diyabetli yaşlıların sağlıklı yaşam biçimi davranışlarının hipertansiyon ve kanser tanılı yaşlılara göre daha iyi olduğunu göstermektedir. Hipertansiyon ve kanser tanılı yaşlılara yönelik sağlıklı yaşam biçimi davranışlarını artıracak programların geliştirilmesi, yaşlıların aktif yaşlanma sürecine ve yaşam kalitesinin yükselmesine katkı sağlayacaktır.

Anahtar kelimeler: Hipertansiyon, diyabet, kanser, sağlıklı yaşam biçimi davranışları

Received Date / Geliş tarihi: 10.07.2018, Accepted Date/ Kabul tarihi: 07.05.2019

${ }^{1}$ İzmir Katip Çelebi Üniversitesi Balatçık Kampüsü, İzmir-TÜRKIYE.

${ }^{2}$ İzmir Aile Sosyal Politikalar Bakanlığı, İzmir-TÜRKIYYE.

${ }^{3}$ İzmir Narlıdere Huzurevi Yaşlı Bakım ve Rehabilitasyon Merkezi, İzmir- TÜRKIYE.

*Address for Correspondence / Yazışma Adresi: Medine Yılmaz, İzmir Katip Çelebi Üniversitesi Balatçık Kampüsü, İzmirTÜRKIYE.

E-mail: medine.cyilmaz@ikc.edu.tr

Yılmaz M, Uyanık G, Böckün E, Tokem Y, Tekin N. Kronik Hastalıklı Yaşlılarda Sağlıklı Yaşam Biçimi Davranışlarının İncelenmesi. TJFMPC, 2019;13(3): 248-257.

DOI: $10.21763 /$ tjfmpc.442410 


\section{GíRiş}

Tıp ve teknoloji alanındaki gelişmeler, tanı ve tedavi yöntemlerinin gelişmesi, temel sağlık hizmetleri ve koruyucu sağlık hizmetlerine verilen önemin artması sonucu yaşlı nüfusun artışına paralel olarak kronik hastalığı olan birey sayısı da artmaktadır. ${ }^{1}$ Kronik hastalıklar genetik, fizyolojik, çevresel ve davranışsal faktörlerin birleşiminin bir sonucudur ve uzun süreli olma eğilimindedir. Dünyada her yıl 40 milyon insan kronik hastalıklar nedeniyle ölmektedir ve bunun 15 milyonunu 30-69 yaş aralığındaki bireyler oluşturmaktadır. ${ }^{1} \mathrm{Bu}$ ölümlerin \%46,2'si kardiyovasküler hastalıklar, $\% 21,7$ 'si kanser ve \%4'ü diyabet kaynaklıdır. ${ }^{2}$ Birçok ülkede ilk beş ölüm nedeni arasında yer alan bu hastalıkların ülkesel ve küresel maliyetleri artmaktadır. $\mathrm{Bu}$ hastalıkların görülme sıklığı, yaş, cinsiyet, ırk, beslenme alışkanlıkları, genetik özellikler ve çevresel etkenlere bağlı olarak toplumdan topluma farklılık göstermektedir. ${ }^{3}$

Obezite dünya genelinde kronik hastalıklar, yeti yitimi ve mortalitenin temel nedenidir ve yaşlilar ile sosyal yönden dezavantajlı olan sınıflar başta olmak üzere tüm yaşları ve sosyal sinıfları etkilemektedir. ${ }^{4}$ Obezitenin belirlenmesinde kullanılan en yaygın metrik sınıflandırma sistemi Beden kütle indeksi (BKİ)'dir. ${ }^{5}$ Bununla birlikte obezitenin metabolik komplikasyonları ile ilişkili olan vücut yağ dağılımı hakkında BKI'nin yeterli bilgi vermemesi nedeniyle günümüzde BKİ'ne ek olarak bel-kalça oranı da yaygın olarak kullanılmaktadır., ${ }^{5,6}$ Nitekim yapilan araştırmalar kardiyovasküler risk faktörleri ile bel çevresi ölçütleri arasında güçlü bir pozitif ilişki olduğunu ve değerlendirmede tek başına BKI yerine bel-kalça oranının da kullanılabileceğini belirtmektedir. ${ }^{7}$

Kronik hastalıkların oluşumunun önlenmesine yönelik birinci basamak hizmetlerinin sunulması sağlı bakım hizmetinin önemli bileşenlerindendir. Bununla birlikte birinci basamakta sunulan kronik hastalık önleme çalışmalarına karşın kronik hastalık gelişen bireylerde gelecekte oluşabilecek komplikasyonların önlenmesi ve yaşam kalitelerinin artırılması da önemlidir. $\mathrm{Bu}$ yönüyle kronik hastalıklı bireylerin olumlu sağlıklı yaşam biçimi davranışını kazanmaları kaçınılmazdır. Sağlıklı yaşam biçimi, bireyin sağlığını etkileyebilen tüm davranışlarını kontrol etmesi ve günlük aktivitelerini düzenlemede kendi sağlık durumuna uygun davranışları seçerek düzenlemesi olarak tanımlanmıştır. ${ }^{8,9}$ Sağlıklı yaşam biçimi davranışları dengeli beslenme, yeterli ve düzenli egzersiz yapma, tütün-alkol kullanmama, hijyenik önlemler alma ve stres yönetimi gibi uygulamaları kapsar. ${ }^{8}$ Bireylerin bu uygulamaları yapabilmeleri ve sürdürebilmeleri için engellerin, kolaylaştırıcıların ve algıladıkları yararların neler olduğunun bilinmesi atılacak adımlar için yol gösterici olacaktır. $\mathrm{Bu}$ araştırmanın amacı kanser, hipertansiyon ve diyabet hastalığı olan yaşlı bireylerin sağlıklı yaşam biçimi davranışlarının incelenmesidir.

\section{YÖNTEM}

\section{Evren- Örneklem}

Araştırma, T.C. İzmir İli Aile ve Sosyal Politikalar Bakanlığı'na bağlı bir Yaşı Bakım ve Rehabilitasyon Merkezi Dinç Yaşlı Bloklarında yürütülmüştür. Araştırmanın yürütüldüğü Dinç Yaşlı Bloklarında günlük yaşam aktivitelerini bağımsız olarak yerine getirebilen sakinler kalmakta, sağlık hizmetleri birinci basamak sağlık hizmetleri çerçevesinde, aile hekimleri, kurum hemşireleri ve bakım personeli tarafından verilmektedir. Merkeze kendi veya birinci derece yakınları Emekli Sandığı emeklisi 60 yaş üzeri yaşlılar alınmaktadır. Merkez bünyesinde tıbbi ve sosyal hizmetler sunulmaktadır. Merkeze kayıtlı olan Dinç Yaşlı Bloklarında kalan 792 kişiden kanser/hipertansiyon/diyabet tan1l1 450 yaşlı bulunmaktadır. Araştırmanın örneklemini araştırmaya alınma kriterlerine uygun (en az 6 ay önce tanı almış, kanser, hipertansiyon ve diyabet tanılarından en az birine sahip olan ve araştırmaya katılmayı kabul eden) yaşlılar oluşturmuştur (n: 304, katılım oranı \%67,5). Araştırmaya nöro-psikiyatrik hastalığı olan (Alzheimer, demans vb) yaşlılar alınmamıştır.

\section{Veri Toplama Araçları}

Yaşlı Görüşme Formu: Yaşlıların sosyodemografik verilerini, antropometrik ölçümlerini, sağlık/ hastalık durumlarını ve sağlıklı yaşam biçimi davranışlarını belirlemek amacıyla araştırmacılar tarafından literatürden yararlanılarak hastalık tiplerine özgü oluşturulmuştur (kanser formu 20 soru, hipertansiyon formu 18, diyabet formu 19 soru). ${ }^{9-15}$ Kanser, diyabet veya hipertansiyon tanılarından herhangi ikisinin varlığı birden fazla kronik hastalık olarak tanımlanmıştır.

Bel Kalça Oranı: Yetişkinlerde bel/kalça oranı kronik hastalıklar için risk değerlendirmesi amacıyla kullanılır. Bel/kalça 
oranı erkeklerde 1,0, kadınlarda 0,8 üzerine çıkmamalıdır. Katılımcıların en alt kaburga kemiği ile krista iliyak arasındaki orta noktadan geçen çevre mezür ile ölçülerek bel çevresi değerlendirilmiştir. Kalça çevresi ise bireyin yan tarafinda durularak, kalçanın en yüksek noktasından ölçülmüştür. Hesaplamada $\mathrm{Bel} /$ Kalça Oranı $==\frac{\text { Bel çevresi }(\mathrm{cm})}{\text { Kalça çevresi }(\mathrm{cm})}$ formülü kullanılmıştır. ${ }^{16}$

Beden Kütle İndeksi (BKİ): Vücut ağırlığının BKI'ne göre değerlendirilmesi en pratik yöntemdir. Yetişkinlerde BKİ 18,5 altında "zayıf", 18,5-24,9 arasinda "normal", 25,0-29,9 arasında "hafif kilolu", 30,0-39,9 arasinda “obez", 40,0 ve üzerinde "morbid obez" olarak sınıflandırılır. ${ }^{6}$ Katılımcıların BKİ değeri; ağırlık ve boy ölçümü yapıldıktan sonra BKI = $\frac{\text { Ağırlık (kg) }}{\text { Boy }^{2}}$ formülüyle hesaplanmıştır. ${ }^{16}$

Sağlıklı Yaşam Biçimi Davranışları Ölçeği-II (SYBDÖ-HLSB-II): Yaşlıların sağlıklı yaşam biçimi davranışlarını belirlemek amacıyla kullanılan ölçek, Walker ve arkadaşları (1987) tarafından geliştirilmiş, 1996 yılında revize edilmiştir. ${ }^{17}$ Türkçe geçerlik ve güvenirlik çalışması, Bahar ve arkadaşları tarafından 2008 yılında yapılmıştır. ${ }^{18}$ Ölçek 52 maddeden, altı alt boyuttan (Sağlık sorumluluğu, fiziksel aktivite, beslenme, manevi gelişim, kişilerarası ilişkiler ve stres yönetimi) oluşmaktadır. Ölçek 4'lü likert tipinde derecelendirilmektedir (Hiçbir zaman, bazen, sık sık, düzenli olarak). Ölçeğin tamamından alınabilecek en düşük puan 52, en yüksek puan 208'dir. Sağlıklı Yaşam Biçimi Davranışları Ölçeği- II'nin Cronbach Alpha katsayısı 0,92 olup bbu araştırmada 0,88 bulunmuştur.

\section{Verilerin Toplanması}

Veriler araştırmacılar tarafından yüz yüze görüşme yöntemiyle kendi odalarında ya da dinlenme salonlarında, yaşlının görüşmek istediği saatlerde toplanmıştır.

\section{Araştırmanın Etik Yönü}

Veriler İzmir Kâtip Çelebi Üniversitesi Girişimsel Olmayan Klinik Araştırmalar Etik Kurul izni ve İzmir Aile, Çalışma ve Sosyal Hizmetler İl Müdürlüğü'nden alınan kurum izni ile katılımcılardan yazılı onam alınarak toplanmıştır.

\section{İstatistiksel Yöntem}

Araştırmadan elde edilen verilerin analizi bilgisayarda istatistik paket programında (SPSS 22.0) gerçekleştirilmiş, sosyodemografik özellikler sayı ve yüzde dağılımları ile analiz edilmiş, nicel verilerin normal dağılıma uygunluk analizi yapılarak parametrik testler (varyans analizi, independent sample t testi) kullanılmıştır. \%95 güven aralığında $\mathrm{p}<0,05$ istatistiksel olarak anlamlı kabul edilmiştir.

\section{BULGULAR}

Araştırmaya katılan bireylerin yaş ortalaması 78,9 7,6 (min:60; max:95) dır. Yaşlıların \%5,3’ü (n:16) kanser, \%26's1 (n:79) Diyabetes Mellitus (DM), \%49,7’si (n:151) Hipertansiyon (HT) hastası olup \%19,1'inin (n:58) birden fazla kronik hastalığı vardır.

Yaşlıların tanı grubu, yaş ve cinsiyete göre SYBDÖ toplam puanları incelendiğinde tüm yaş gruplarında ve her iki cinsiyette en yüksek SYBDÖ puanının diyabetli yaşlılarda olduğu görülmektedir. En düşük SYBDÖ puanları ise 65-74 yaş grubunda ve erkeklerde iki ve daha fazla kronik hastalığ 1 olanlarda, 75-84 yaş grubunda kanserli yaşlılarda, 85 ve üzeri yaş grubunda hipertansiyonlu yaşlılarda, kadınlar arasında ise kanserli yaşlılardadır (Grafik 1). Kanserli yaşlıların \% 93,7'sinin (n:15) solid organ tümörü tanıs1 vardır. Kanser tanıs1 aldıktan sonra geçen zaman medyan 4 yıldır (min:1 yıl; maks:27 yıl). Bu yaşlıların \%43,8'i (n:7) cerrahi tedavi, \%31,3'ü (n:5) kemoterapi, $\% 25,1$ 'i (n:4) hem kemoterapi (KT) hem radyoterapi (RT) görmüş olup, \%31,3'ünün $(\mathrm{n}: 5)$ tedavisi halen devam etmektedir. Yaşliların kanser tedavileri bittikten sonra geçen süre medyan 8 yıldır (min:1 yıl- maks:40 yıl). Yaşlıların \%23,1'i yılda bir, \%11,5'i üç ayda bir, \% 7,7'si, alt1 ayda bir kez, \%7,7'si ayda bir kez kontrole gitmektedir. Kanser hastalarının \%75'inin kansere eşlik eden bir kronik hastalığı bulunmaktadır. Bu hastalıklar sırasıyla kalp hastalığı $(\% 18,8)$, osteoporoz $(\% 12,5)$ diyabet $(\% 6,3)$ ve diğer hastalıklardır (\% 31,5). Yaşlıların \%31'inin kanser dış1 nedenlerden dolayı yakınmaları olup, tansiyon yüksekliği, katarakt, vertigo ve herni eşit oranda $(\% 6,3)$ görülmektedir. Yaşlıların \%93,8'i (n:15) düzenli ilaç kullanmaktadır. Kullanılan ilaç sayısı medyan 3 (min:1; max:8) tür. Altıdan fazla ilaç kullanan kanserli yaşlıların SYBDÖ puanı, daha az ilaç kullananlardan yüksektir ( $\mathrm{F}=4,517 ; \mathrm{p}: 0,037)$ (Tablo 1). 


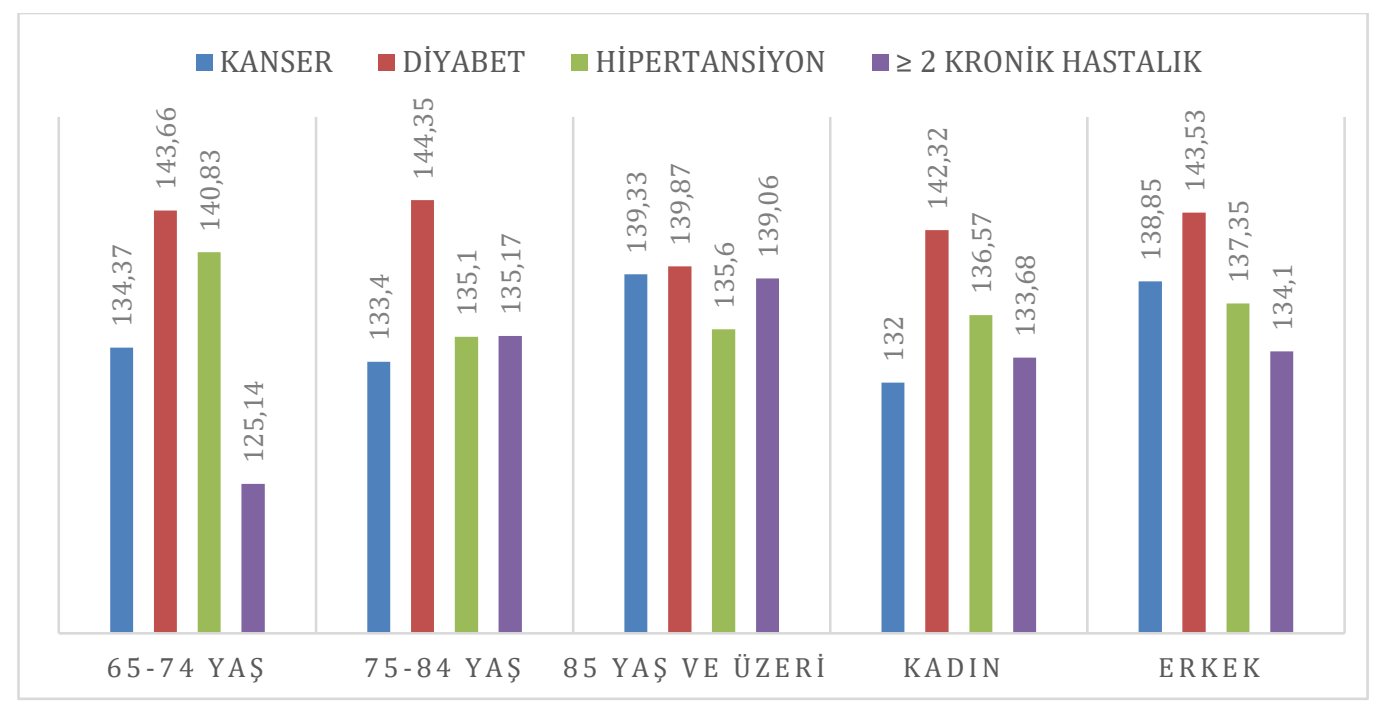

Grafik 1. Yaşlıların tanı grubu, yaş ve cinsiyete göre SYBDÖ toplam puanları

\section{Diyabet Tanılı Yaşlılara İlişkin Bulgular}

Diyabetli yaşlıların diyabetle geçen yaşam süresi medyan 15 yıldır (min:1 yıl; max:50 y1l). Yaşlıların $\% 43$ 'ünde diyabetin komplikasyonlarından en az birisi olup, $\% 17,7$ 'sinde (n:14) retinopati, \%7,6'sinda (n:6) nöropati, \%7,6'sında (n:6) nefropati vardır. Yaşlıların \%10,1'i (n:8) birden fazla komplikasyonu birlikte deneyimlemektedir. Diyabetli yaşlıların \%48,1'i (n:38) insülin kullanmaktadır. İnsülin kullanım süresi ortalama medyan 6 yıldır (min:1 ay; max: 40 yı1). Yaşlıların \% 15,2'si (n:12) diyabet nedeniyle en az bir kez hastaneye yatmıştır. Hastane yatış1 medyan 2 (min:1; max:5) dir. Diyabetli yaşlıların \%41,8'inin diyabete ek bir kronik hastalığı bulunmakta, en sik sirasıyla kalp hastalığı $(\% 24,1)$, guatr $(\% 3,8)$, kronik böbrek yetmezliği $(\% 2,5)$ görülmektedir. Ekstremitelerde ağrı $(\% 11,4)$, bel ağrısı $(\% 5,1)$, mide yanması ve yorgunluk $(\% 3,8)$, ellerde tremor $(\% 2,5)$ en sik yaşanan semptomlardır. Diyabetli yaşlıların \%94,9'u düzenli ilaç kullanmaktadır. Kullanılan ilaç sayısı medyan 3 (min:1; max:11) tür. Diyabet hastalarının \%69,6'sının birinci derece yakınlarında kronik bir hastalık bulunurken, \%39,2'sinin ise ailesinde diyabet tanılı birey bulunmaktadır. Tanı gruplarına göre sosyal aktiviteler incelendiğinde sosyal aktivite yapan diyabetli yaşlıların yapmayanlara göre SYBDÖ ölçek puanları yüksek bulunmuştur ( $(=1,997 ; \mathrm{p}: 0,049)$ (Tablo 1).

\section{Hipertansiyon Tanılı Yaşlılara İlişkin Bulgular}

Hipertansiyon tanılı yaşlıların hipertansiyonla geçen yaşam süresi medyan 13 yıldır (min:1 yıl; max:38 y1l). Yaşlılarda hipertansiyonun en az bir belirtisinin görüldüğ̈̈ ( $\% 40,4 ; n: 61)$, en yüksek oranda baş dönmesi $(\% 15,9)$ ve baş ağrıs1 $(\% 11,9)$ yaşadıkları belirlenmiştir. Hipertansiyonlu yaşlıların \%34,4'ünün (n:52) eşlik eden bir başka kronik hastalığı bulunmakta, en yüksek oranda $(\% 13,2)$ kalp hastalığ 1 görülmektedir. Yaşlıların düzenli kullandığ1 ilaç sayısı medyan 2 (min:0; max:17)'dir. Kullandığı ilaç sayısı altıdan fazla olan yaşlıların SYBDÖ puanları dört ilaçtan az kullananlardan yüksektir ( $\mathrm{F}=4,112 ; \mathrm{p}: 0,018)$ (Tablo 1). Yaşlıların \%29,8'si (n:45) HT nedeniyle en az bir kez hastaneye yatmıştır. Tablo 2'de tanı gruplarına göre yaşlıların SYBDÖ toplam ve alt ölçek puanları, BKİ ve bel kalça oranları karşılaştırılmıştır. Buna göre; kanserli yaşlıların sağlık sorumluluğu alt ölçek puanı iki ve üzeri kronik hastalık tanısı olan yaşlılardan yüksektir ( $\mathrm{F}=4,103 ; \mathrm{p}: 0,007)$. Diyabetli yaşlıların fiziksel aktivite, manevi gelişim alt ölçek puanları ve SYBDÖ toplam puanı, iki ve üzeri kronik hastalık tanısı olan gruptan yüksektir. Diyabetli yaşlıların stres yönetimi alt ölçek puanı, HT ve iki ve üzeri kronik hastalık tanısı olan yaşlılardan yüksektir $(\mathrm{F}=6,372 \mathrm{p}: 0,000)$. Yaşlıların tanı gruplarına göre beslenme ve kişilerarası ilişkiler alt ölçek puan ortalamaları, hastalık tanılarına göre bel/kalça oranları farklılaşmamaktadır $(p>0,05)$. BKİ değerine göre tanı grupları karşılaştırıldığında kanserli yaşlıların BKI'si diğer tanı gruplarından daha düşük bulunmuştur $(\mathrm{F}=4,517 ; \mathrm{p}: 0,004)$. İki ve daha fazla kronik hastalığı olan yaşlıların hasta olarak geçirdikleri süre ile SYBDÖ toplam puanı arasında negatif yönlü, zayıf düzeyde anlamlı bir ilişki vardır $(\mathrm{r}=-0.292 ; \mathrm{p}<0,01)$. 
Tablo 1. Katılımcıların tanı gruplarına göre bazı özellikleri

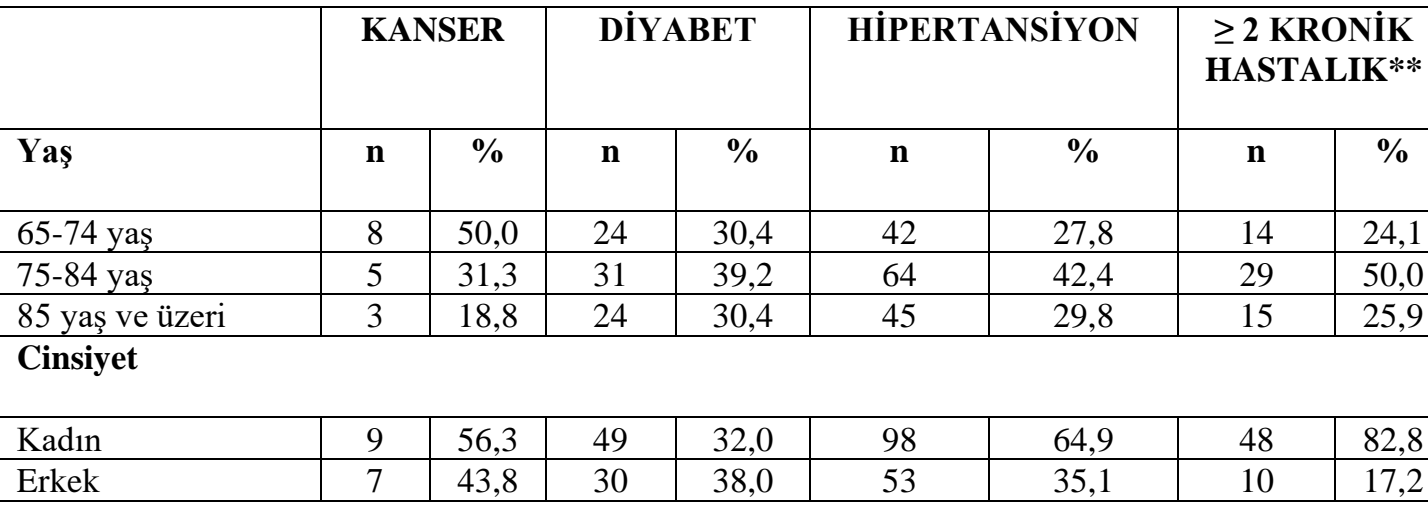

Eğitim düzeyi

\begin{tabular}{|c|c|c|c|c|c|c|c|c|}
\hline Temel öğrenim & 2 & 12,5 & 26 & 32,9 & 43 & 28,5 & 26 & 44,8 \\
\hline Lise ve üzeri & 14 & 87,5 & 53 & 67,1 & 108 & 71,5 & 32 & 55,2 \\
\hline \multicolumn{9}{|l|}{ BKI* } \\
\hline$<24.99$ & 8 & 50,0 & 23 & 29,1 & 41 & 27,2 & 9 & 15,5 \\
\hline$\geq 25.0$ & 8 & 50,0 & 56 & 70,9 & 105 & 69,5 & 48 & 82,8 \\
\hline \multicolumn{9}{|l|}{ Bel/Kalça } \\
\hline$>0,8$ (Kadın) & 8 & 100 & 45 & 97,8 & 87 & 93,5 & 48 & 100,0 \\
\hline$>1,0($ Erkek $)$ & - & - & 5 & 17,2 & 9 & 18,4 & 8 & 80,0 \\
\hline \multicolumn{9}{|l|}{ İlaç Sayısı } \\
\hline$<4$ & 9 & 56,3 & 47 & 59,5 & 110 & 72,8 & 35 & 60,3 \\
\hline$\geq 4$ & 7 & 43,7 & 18 & 22,8 & 27 & 17,9 & 21 & 36,2 \\
\hline
\end{tabular}

Sigara kullanımı

\begin{tabular}{|c|c|c|c|c|c|c|c|c|}
\hline Hala içen & 4 & 25,0 & 9 & 11,4 & 12 & 7,9 & 5 & 8,6 \\
\hline $\begin{array}{l}\text { Hiç içmemiş/ } \\
\text { Bırakmış }\end{array}$ & 12 & 75,0 & 69 & 87,3 & 139 & 92,1 & 53 & 91,4 \\
\hline \multicolumn{9}{|l|}{ Alkol kullanımı } \\
\hline Kullanıyor & 5 & 31,3 & 16 & 20,3 & 32 & 21,2 & 10 & 17,2 \\
\hline Kullanmiyor & 11 & 68,8 & 63 & 79,7 & 119 & 78,8 & 48 & 82,8 \\
\hline \multicolumn{9}{|l|}{ Sosyal aktivite } \\
\hline Var & 7 & 43,8 & 39 & 49,4 & 71 & 47,0 & 32 & 55,2 \\
\hline Yok & 9 & 56,3 & 40 & 50,6 & 78 & 51,7 & 26 & 44,8 \\
\hline \multicolumn{9}{|c|}{ Sağlık durumu değerlendirmesi } \\
\hline Çok iyi-iyi & 6 & 37,5 & 40 & 50,6 & 74 & 49,0 & 28 & 48,3 \\
\hline Orta & 5 & 31,3 & 31 & 39,2 & 60 & 39,7 & 23 & 39,7 \\
\hline Kötü - Çok kötü & 5 & 31,3 & 8 & 10,1 & 17 & 11,3 & 7 & 12,1 \\
\hline TOPLAM & 16 & 100,0 & 79 & 100,0 & 151 & 100,0 & 58 & 100,0 \\
\hline
\end{tabular}

*Diyabetli bireylerin \%2,5 (n:2)'i zayıftır.

**Kanser, DM, HT tanılarından en az ikisine sahip olmak 
Tablo 2. Yaşılırın tanı gruplarına göre SYBD ölçek puanları, BKİ ve Bel/Kalça Oranları

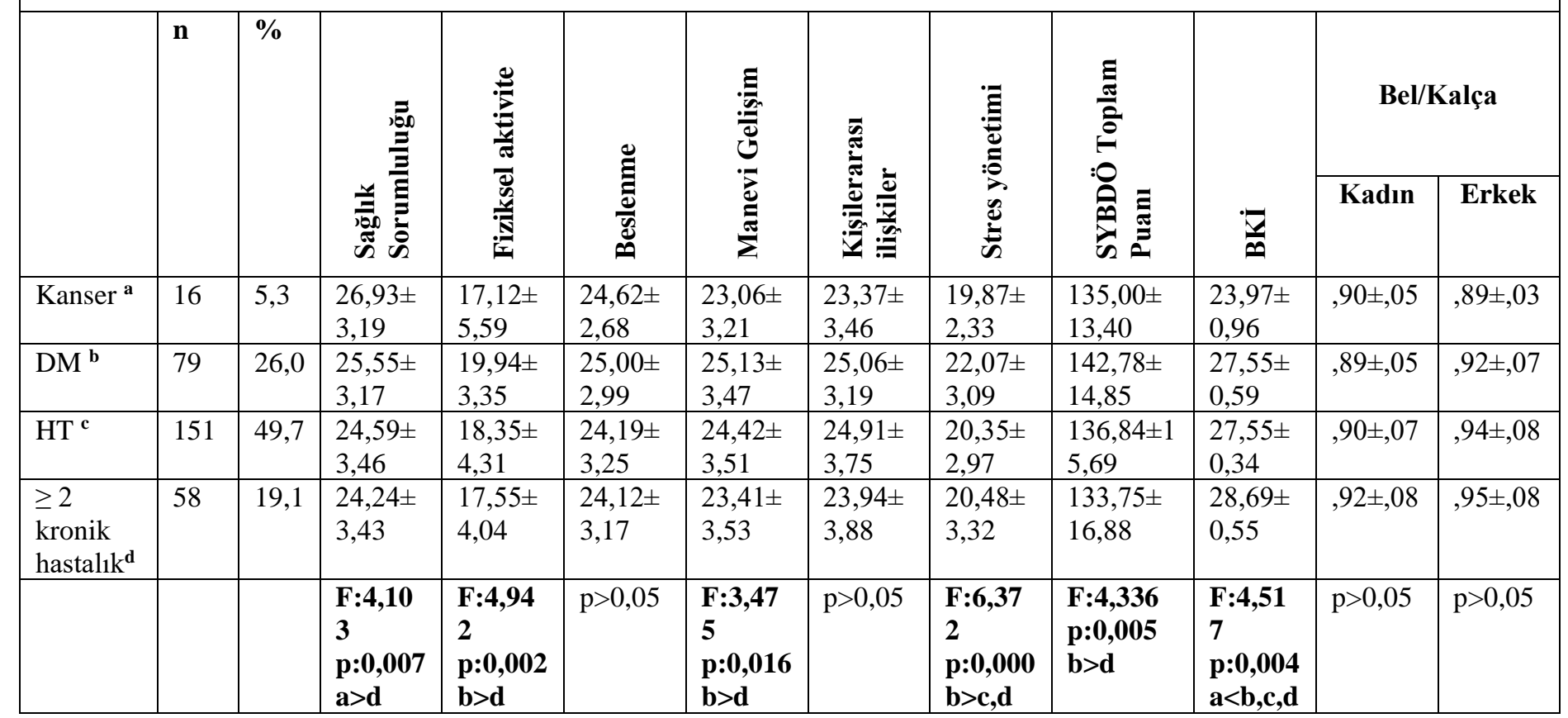




\section{TARTIŞMA}

Yürütülen bu araştırmada huzurevinde kalan kanserli, diyabetli ve hipertansiyonlu yaşlıların sağlıklı yaşam biçimi davranışlarına odaklanılmıştır. Literatürde var olan çalışmaların ise daha çok kronik hastalık ayrımı yapmaksızın huzurevinde kalan yaşlıların sonuçlarını ya da hastaneye başvuran/hastanede kalan kronik hastalığı olan yaşlıların sağlık davranışlarının sonuçlarını gösterdiği belirlenmiştir. Huzurevinde kalan bireylerin sonuçlarını göstermesi açısından literatüre katkı sağlayan bu araştırmada yaşlıların daha çok orta yaşlı grubunda ve hipertansiyon tanısına sahip olduğu, yaklaşık her beş yaşlıdan birinin birden fazla kronik hastalığı olduğu, hangi tanıdan olursa olsun ilaç kullanım sayılarının fazla olduğu da tespit edilmiştir.

Bu çalışmadan elde edilen SYBDÖ puanları huzurevinde kalan kronik hastalıklı yaşlıların yaşam biçimi davranışlarının orta düzeyde olduğunu göstermektedir. Li ve Zhang'ın çalışmasında hipertansiyonlu bireylerde SYBDÖ puanı çok düşük $(72.2 \pm 16.6)$ olarak yorumlanmıştır. ${ }^{13}$ Movahedi ve ark.'ları ile Motaghi \& Dolatabadi çalışmalarında yaşlı bireylerin sağlıklı yaşam biçimi davranışlarının orta düzeyde olduğunu bildirmişlerdir. ${ }^{19,20} \mathrm{Bu}$ araştırmanın sonuçları hastanede tedavi gören hipertansiyonlu yaşlı bireylerin, kalp hastası yaşlıların, huzurevinde kalan yaşlıların sonuçları ile benzerdir. ${ }^{9-11}$ Sognh ve ark.'da Koreli göçmen yaşlılarda sağlıklı yaşam biçimi davranışlarının düşük olduğunu bildirmişlerdir. ${ }^{10}$ Gerek yerel gerekse farklı ülke örneklemlerinde yapılan çalışmalar yaşlıların sağlıklı yaşam biçimi davranışlarının orta düzeyde olduğunu göstermiştir. $\mathrm{Bu}$ sonuçlar yaşlı bireylerin farklı kültür ve koşullarda da olsa sağlik ve sosyal gereksinimlerinin benzer olduğuna işaret etmektedir.

Sağlıklı yaşam biçimi davranışlarından beslenme alt boyutunda kronik hastalık tiplerine göre farklılık olmadığı görülmüştür. Nitekim yaşlıların hastalık tanılarına göre de bel/kalça oranları farklılık göstermemektedir. Yanı sıra kanserli yaşlılar daha düşük beden kütle indeksine sahiptirler. Kanserli bireylerin kanser tedavisinin yan etkilerine bağlı olarak gelişen malnütrisyon ve sarkopeni nedeniyle daha düşük beden kütle indeksine sahip olmaları beklenen bir sonuçtur. Bu duruma karşın hem diyabetli hem de hipertansiyonlu yaşlıların "kilolu" grubunda yer almaları etkin kronik hastalık yönetimi açısından olumsuz bir durum olarak yorumlanabilir. Ayrıca birden fazla kronik hastalığı olan yaşlıların BKI' lerinin daha yüksek olduğu da göze çarpmaktadır. Bu yükseklik, kurumda düzenli beslenme uygulamalarına kolay ulaşma durumları ve fizik aktivite düzeylerinin düşük olması ile açıklanabilir. Mollaoğlu ve Solmaz'ın çalışmasında da hipertansiyonlu yaşlıların SYBDÖ beslenme puanı düşük bulunmuştur. ${ }^{11} \mathrm{Bu}$ çalışmanın aksine hastaneye check-up için giden yaşlılarda, Koreli göçmen yaşlilarda en yüksek skor beslenme boyutunda bulunmuştur. ${ }^{13,21} \mathrm{Bu}$ sonuçlar, huzurevinde kalan yaşlılara yönelik yürütülecek sağlıklı beslenme, egzersiz ve fizik aktivite programlarının önemini ortaya çıkarmaktadır. Yaşlıların sağlı durumlarına uygun yürütülecek fizik aktivite uygulamaları etkin kilo yönetimine ve dolayısı ile kronik hastalığın da etkin yürütülmesine katkı sağlayacaktır.

Kanser tanılı yaşlıların sağlık sorumluluğu düzeylerinin DM ve HT'li yaşlılara göre daha yüksek olduğu görülmüştür. Bu durum kanserin diğer kronik hastalıklara göre daha ciddi seyir göstermesi ve toplum tarafından daha ölümcül olarak algılanması ile ilgili olarak hastalığa verilen önemin artmasıyla ilişkilendirilebilir. Hastaneye kontrol için giden yaşlıların sağlıklı yaşam biçimi davranışlarının incelendiği çalışmada da sağlık sorumluluğu en düşük bulunmuştur. ${ }^{13}$ Yaşlılık sürecine bağl1 gelişen fizyolojik değişikliklerin beraberinde getirdiği semptomlar yaşlılar tarafindan olağan karşılanabilmekte ve sağlık hizmeti kullanımını olumsuz etkileyebilmektedir. Tüm bunlar göz önünde bulundurulduğunda yaşlılara sağlıklı yaşam biçimi davranışlarının kazandırılması ve sürdürülebilir kılınması, sağlık sorumluluğunun yükseltilmesi ile etkin kronik hastalık yönetimi sağlanabilir.

$\mathrm{Bu}$ araştırmada diyabetli bireylerin fiziksel aktivite yapma oranları ve Fiziksel Aktivite ölçek puanları kanser ve hipertansiyon tanılı yaşlilara göre daha yüksektir. Bu sonuç etkin diyabet hastalığı yönetimi için yaşlıların diyabet yönetiminde etkili olan fiziksel aktivite yapmanın gerekliliğine inandıklarını göstermektedir. $\mathrm{Bu}$ araştırmada olduğu gibi hipertansiyonlu yaşlılar ile yapılan araştırmada da fiziksel aktivite puanı düşük bulunmuştur. ${ }^{11}$ Aynı ölçme aracının kullanıldığı iki araştırmada da en düşük alt boyutun fizik aktivite alanında olduğu belirlenmiştir. ${ }^{14,21}$ Kronik hastalık tipine bakmaksızın hastaneye kontrole giden yaşlılarda da fiziksel aktivite alt ölçek puanı en düşük bulunmuştur. ${ }^{13}$ Yaşlıların yaşla birlikte fiziksel fonksiyonlarının azalması, çabuk yorulma, anemi, yeterli beslenmeme gibi nedenlerle fiziksel aktivite yapmada isteksiz oldukları, düşme ve kırık tehlikesi nedeniyle 
risk almak istemedikleri, birçok yaşlının artrit gibi romatizmal hastalı ya da osteoporoz tanısı olmaları nedeniyle de yaralanabileceklerini, semptomların artacağı düşüncesiyle egzersiz yapma konusunda isteksiz oldukları bildirilmektedir. ${ }^{22,23}$

Kişilerarası ilişkiler alt boyut puanları tanı gruplarına göre farklılık göstermemektedir. Farklı tipte kalp hastalığı olan yaşlılarla yürütülen araştırmada da tanı gruplarına göre kişilerarası ilişki puanı değişmemektedir.9. Japonya ve Amerika Birleşik Devletlerin'de (ADB) yaşayan hipertansiyonlu yaşlıların karşılaştırıldığı araştırmada ABD'deki yaşlılar en yüksek puanı SYBDÖ'nün kişilerarası ilişkiler alt boyutundan alırken, Japonya'daki yaşııların kişilerarası iliş̧iler puanının ABD'de yaşayanlardan daha yüksek olduğu bulunmuştur. ${ }^{14}$ Kişilerarası ilişki puanı evde yaşayan yaşlılarda kurum bakımı alanlara göre, eğitim düzeyi yüksek olan yaşlılarda düşük olanlara göre daha yüksek bulunmuştur. ${ }^{11,21,24}$ Sözü edilen araştırmalar göz önünde bulundurulduğunda yaşlıların kişilerarası ilişki puanlarının yaşadıkları yer, kültür, eğitim düzeyi gibi sosyodemografik özelliklerden etkilendiği ancak hastalık tanılarına göre değişmediği görülebilir.

İki farklı ülkede yaşayan yaşlıları karşılaştıran çalışma sonuçlarının aksine, bu araştırmada diyabet tanılı yaşlılarda stres yönetimi ve manevi gelişim alt boyutları, kanser ve hipertansiyon tanılı yaşlılara göre daha yüksek bulunmuştur. ${ }^{14}$ Nitekim bu yaşlıların genel sağlıklı yaşam biçimi davranışı puanları da özellikle birden fazla tanıya sahip olan yaşlilara göre daha yüksektir. Bu sonuç hastane/kurumlarda diyabete yönelik yürütülen diyabet özyönetim eğitimlerinin olumlu bir yansıması olabilir. ${ }^{25,26}$

Bazı çalışmalarda yaş, cinsiyet, eğitim durumu, ${ }^{13}$ medeni durum, ${ }^{10,11}$ gelir, ${ }^{13}$ sağlığ 1 $\operatorname{alg}_{1} \operatorname{mama}^{10,13}$ gibi sosyodemografik özelliklerin sağlıklı yaşam biçimi davranışları ile ilişkili olduğu bildirilmiştir. Buna karşın diğer araştırmalarda olduğu gibi bu araştırmada da yaş, cinsiyet $^{27}$ ve medeni duruma ${ }^{10,14,28,29}$ göre bir fark belirlenmemiştir. $\mathrm{Bu}$ araştırmada sadece eğitim düzeyinin SYBDÖ ile ilişkili olduğu görülmüştür. Eğitim düzeyi yüksek bireylerde olumlu sağlıklı davranışları daha fazladır. Birden fazla kronik hastalığ yaşlılarda hastalıkla geçen sürenin artmasına bağlı olarak sağlıklı yaşam biçimi davranışı olumsuz etkilenmektedir. Kronik hastalıkla birlikte yaşamanın getirdiği durum yaşlıların farkındalığının düşük olmasına ve olumsuz yaşam biçimi davranışlarının sürdürülmesine neden olabilir. Bu yaşlılara yönelik kronik hastalıkların beraberinde getireceği komplikasyonlar ve bunların yaşam kalitesi üzerine etkisini hatırlatıcı ve pekiştirici bireysel eğitimlerin yürütülmesi etkili olacaktır.

Bireyin sosyal olarak aktif olması sağlıklı yaşam biçiminin olumlu bir göstergesidir. ${ }^{2,30,31}$ Araştırmada diyabetli yaşlıların daha çok sosyal aktivite içinde olduğu ve bu yaşlıların sağlıklı yaşam biçimi davranışlarının daha iyi olduğu görülmüştür. $\mathrm{Bu}$ bulgular farklı araştırmaların bulgularını desteklemektedir. ${ }^{12,32}$ İlerleyen yaş ile birlikte, bireylerin aktif sosyal ağları koruması, mevcut ilişkileri sürdürmesi ve yeni ilişkiler kurabilmesinin zorlaştığı göz önünde bulundurulduğunda aktif yaşlanma ve yaşam kalitesi açısından sosyal katılım daha fazla önem kazanmaktadır. ${ }^{33}$ Yaşliların toplum katılımını artıracak ve sürdürülebilirliğini sağlayacak stratejilerin geliştirilmesi, sağlıklı yaşam biçimini de destekleyecektir.

\section{Sinırlılıklar}

Verilerin yaşlıların öz bildirimine dayalı toplanmış olmasının ve ilerleyen yaşta hafıza kayb1 faktörünün, veri güvenirliğini etkilemiş olabileceği gözönünde bulundurulmalıdır.

\section{SONUÇ ve ÖNERILLER}

$\mathrm{Bu}$ araştırma huzurevinde yaşayan hipertansiyon, kanser ve diyabet tanılı yaşlılarda sağlıklı yaşam biçimi davranışlarını inceleyen ilk çalışmadır. Araştırma bulguları diyabet tanılı yaşlıların, kanser ve hipertansiyon tanılı yaşlılara göre olumlu sağlık davranışlarının daha fazla olduğunu göstermektedir. Yaşlı bireylere olumlu sağlıklı yaşam biçimi davranışları kazandırılması hususunda huzurevlerinde istihdam edilecek halk sağlığı hemşireleri çeşitli programlar geliştirebilir ve aktif olarak yürütebilirler. Ayrıca kurumda yaşayan kanser, diyabet ve hipertansiyon tanılı yaşlılar için aile hekimleri ile halk sağlığı alanında çalışan hemşirelerin, bütüncül interdisipliner ekip girişimleri yürütmesi ile etkin kronik hastalık yönetimi yapılabilecektir. Özellikle aktivite toleransına bağlı olarak yürüme, kas güçlendirme egzersizleri, tai chi gibi fiziksel aktivite programlarının ve stresle baş etme programlarının yürütülmesi ön plana çıkmaktadır. Ayrıca kronik hastalığı olan yaşlılara yönelik olarak yürütülecek programlara (beslenme, egzersiz, sigara- alkol tüketimini önleme, stres yönetimini içeren yapılandırılmış) ve bu programların etkinliğini 
gösterecek çalışmalara gereksinim vardır. Tüm bunlar birinci basamakta birçok alanda yürütülecek etkin girişimlerle uzun vadede kronik hastalığı olan yaşlıların yaşam kalitesine olumlu katkı sağlayacaktır.

\section{Çıkar Çatışması}

Yazarlar arasında herhangi bir çıkar çatışması bulunmamaktadır.

\section{KAYNAKLAR}

1. World Health Organization. 'Best Buys' And Other Recommended Interventions For The Prevention And Control Of Noncommunicable Diseases. (2017).

2. World Health Organization. Global Status Report on Noncominicable Diseases. (2014).

3. Kahveci, R. et al. Sağlıklı Yaşlanma ve Kronik Hastalıklar Farkındalık Projesi. (2013).

4. T.C Sağlık Bakanlığı Sağlığın Geliştirilmesi Genel Müdürlüğü Sağlığın Teşviki Daire Başkanlığı. Türkiye Beden Ağırlığı Algıs1 Araştırması. (2012).

5. World Health Organization. Body mass index - BMI. (2018).

6. Nuttall, F. Q. Body mass index: Obesity, BMI, and health: A critical review. Nutr. Today 50, 117-128 (2015).

7. Fauziana, R. et al. Body mass index, waist-hip ratio and risk of chronic medical condition in the elderly population: results from the Well-being of the Singapore Elderly (WiSE) Study. BMC Geriatr. 16, 1-9 (2016).

8. Pender, N. J., Barkauskas, V. H., Hayman, L., Rice, V. H. \& Anderson, E. T. Health promotion and disease prevention: toward excellence in nursing practice and education. Nurs. Outlook 40, 106-120 (1992).

9. Kucukberber, N., Ozdilli, K. \& Yorulmaz, H. Evaluation of factors affecting healthy life style behaviors and quality of life in patients with heart disease. Anadolu Kardiyol. Dergisi/The Anatol. J. Cardiol. 11, 619-626 (2011).

10. Kulakçı, H., Ayyıldız, T. K., Emiroğlu, O. N. \& Köroğlu, E. Huzurevinde Yaşayan Yaşlıların Öz Yeterlilik Algılarının ve Sağlıklı Yaşam Biçimi Davranışlarının Değerlendirilmesi. Dokuz Eylül Üniversitesi Hemşirelik Yüksekokulu Elektron. Derg. 5, 53-64
(2012).

11. Mollaoğlu, M. \& Solmaz, G. Analysis of Healthy Lifestlye Behaviours of Hypertensive Patients. Prim. Heal. Care Open Access 4, (2014).

12. Wu, A. M. S., Tang, C. S.-K. \& Kwok, T. C. Y. Physical and psychosocial factors associated with healthpromoting behaviors among elderly Chinese with type-2 diabetes. J. Health Psychol. 9, 731-40 (2004).

13. Li, S. X. \& Zhang, L. Health behavior of hypertensive elderly patients and influencing factors. Aging Clin. Exp. Res. 25, 275-281 (2013).

14. Kemppainen, J. et al. Health promotion behaviors of residents with hypertension in Iwate, Japan and North Carolina, USA. Japan J. Nurs. Sci. 8, 20-32 (2011).

15. Heymann, A. D., Gross, R., Tabenkin, H., Porter, B. \& Porath, A. Factors associated with hypertensive patients' compliance with recommended lifestyle behaviors. Isr. Med. Assoc. J. 13, 553-557 (2011).

16. Pekcan, G. Beslenme Durumunun Saptanmasi. (2008).

17. Walker, S. N., Volkan, K., Sechrist, K. R. \& Pender, N. J. Health-promoting life styles of older adults: Comparisons with young and middle-aged adults, correlates and patterns. Adv Nurs Sci 11, 76-90 (1988).

18. Bahar, Z., Beşer, A., Gördes, N., Ersin, F. \& Kissal, A. Sağlıklı Yaşam Biçimi Davranışları Ölçeği II'nin Geçerlik ve Güvenirlik Çalışması. 12, (2008).

19. Movahedi, M., Khamseh, F., Ebadi, A., Haji Amin, Z. \& Navidian, A. Assessment of the lifestyle of the elderly in Tehran. J. Heal. Promot. Manag. 5, 51-59 (2016).

20. Motaghi, M. \& Dolatabati, E. D. Lifestyle of elderly people of Isfahan ' s villages in Iran in 2014. Int. J. Humanit. Cult. Stud. 790-803 (2016).

21. Sohng, K. Y., Sohng, S. \& Yeom, H. A. Health-promoting behaviors of elderly Korean immigrants in the United States. Public Health Nurs. 19, 294-300 (2002).

22. Francis, P. W. Physical Activities in Elderly: Benefits and Barriers. (Human Ageing and Elderly Services, 2014).

23. Moschny, A., Platen, P., KlaassenMielke, R., Trampisch, U. \& Hinrichs, T. Barriers to physical activity in older adults in Germany: a cross-sectional study. Int. J. Behav. Nutr. Phys. Act. 8, 
121 (2011).

24. Chilton, L., Hu, J. \& Wallace, D. C. Health-promoting lifestyle and diabetes knowledge in Hispanic American adults. Home Heal. Care Manag. Pract. 18, 378-385 (2006).

25. Deakin, T. A., McShane, C. E., Cade, J. E. \& Williams, R. Group based training for self-management strategies in people with type 2 diabetes mellitus. in Cochrane Database of Systematic Reviews (ed. Steinsbekk, A.) (John Wiley \& Sons, Ltd, 2005). doi:10.1002/14651858.CD003417.pub 2

26. Chodosh, J. et al. Meta-Analysis: Chronic Disease Self-Management Programs for Older Adults. Ann. Intern. Med. 143, 427 (2005).

27. Çelik, A., Kardaş, Ö. \& Karadakovan, A. Huzurevinde Yaşayan Yaşlı Bireylerde Yalnızlık Durumu ve Sağlıklı Yaşam Biçimi Davranışları. İzmir Katip Çelebi Üniversitesi Sağlık Bilim. Fakültesi Derg. 2, 17-23 (2017).

28. Tambağ, H. \& Öz, F. Evaluation of the Psychoeducation Given to the Elderly at Nursing Homes for a Healthy
Lifestyle and Developing Life Satisfaction. Community Ment. Health J. 49, 742-747 (2013).

29. Loef, M. \& Walach, H. The combined effects of healthy lifestyle behaviors on all cause mortality: A systematic review and meta-analysis. Prev. Med. (Baltim). 55, 163-170 (2012).

30. Zanjani, S. et al. Determinants of healthy lifestyle and its related factors among elderly people. J. Educ. Health Promot. 4, 103 (2015).

31. Gottlieb, N. H. \& Green, L. W. Life Events, Social Network, Life-Style, and Health: An Analysis of the 1979 National Survey of Personal Health Practices and Consequences. Health Educ. Q. 11, 91-105 (1984).

32. Toobert, D. J., Hampson, S. E. \& Glasgow, R. E. The Summary of Diabetes Self-Care. Diabetes Care J. 23, 943-950 (2000).

33. Hao, G. et al. Social participation and perceived depression among elderly population in South Africa. Clin. Interv. Aging 12, 971-976 (2017). 